\title{
Continuous noninvasive hemoglobin monitoring estimates timing for detecting anemia better than clinicians: a randomized controlled trial
}

Bo Tang, Xuerong Yu, Li Xu, Afang Zhu, Yuelun Zhang and Yuguang Huang *i]

\begin{abstract}
Background: Hemoglobin measurement is important for transfusion decision-making. Pulse CO-Oximetry provides real-time continuous hemoglobin $(\mathrm{SpHb})$ monitoring. The triage role of $\mathrm{SpHb}$ trends based on hemoglobin measurements was investigated.

Methods: In this diagnostic randomized controlled trial, 69 patients undergoing spine or cytoreductive surgery were randomly enrolled into SpHb-monitoring and standard-care groups. Diagnostic blood samples were drawn for $\mathrm{CO}-$ oximetry $\mathrm{Hb}(\mathrm{CoOxHb})$ when the $\mathrm{SpHb}$ decreased by $1 \mathrm{~g} / \mathrm{dl}$ or at the clinician's discretion in the standard-care group. The positive predictive value (PPV) was defined as the ability to detect a decrease in $\mathrm{CoOxHb}>1 \mathrm{~g} / \mathrm{dl}$ or a CoOxHb $<10 \mathrm{~g} / \mathrm{dl}$; the PPVs were compared using Fisher's exact test. The SpHb and trend accuracies were calculated. The transfusion units and postoperative hemoglobin levels were compared.

Results: The PPV of a decrease in $\mathrm{CoOxHb}>1 \mathrm{~g} / \mathrm{dl}$ was $93.3 \%$ in the $\mathrm{SpHb}$ group vs $54.5 \%$ without $\mathrm{SpHb}$ monitoring $(p=0.002)$. The PPV of $\mathrm{CoOxHb}<10 \mathrm{~g} / \mathrm{dl}$ was $86.7 \%$ vs. $50.0 \%$ for these groups $(p=0.015)$. The $\mathrm{CoOxHb}$ was never $<7 \mathrm{~g} / \mathrm{dl}$ with $\mathrm{SpHb}$ monitoring. Sixty $\mathrm{SpHb}-\mathrm{CoOxHb}$ data pairs and 28 delta pairs $(\Delta \mathrm{SpHb}-\Delta \mathrm{CoO} \times \mathrm{Hb})$ were collected. The bias, precision and limits of agreement were $-0.29,1.03$ and -2.30 to $1.72 \mathrm{~g} / \mathrm{dl}$, respectively. When $\Delta \mathrm{SpHb}$ and $\Delta \mathrm{CoOxHb}$ were $>1 \mathrm{~g} / \mathrm{dl}$, the concordance rate for changes in hemoglobin reached $100 \%$. The delta pairs revealed a positive correlation $[\Delta \mathrm{SpHb}=0.49 * \Delta \mathrm{CoO} \times \mathrm{Hb}-0.13$; $r=0.69,95 \%$ confidence interval $(0.53,0.82)]$. No significant differences were found in the transfusion volume or postoperative anemia state.
\end{abstract}

Conclusions: The SpHb trend tracked changes in hemoglobin satisfactorily during surgery and more accurately estimated the appropriate timing for invasive hemoglobin measurements than the clinicians.

Trial registration: ChiCTR1800016290 (Prospective registered). Initial registration date was 24/05/2018.

Keywords: Pulse CO-oximetry, Hemoglobin, Monitoring, Anemia, Surgery, Trends

\footnotetext{
*Correspondence: garypumch@163.com

Department of Anesthesiology, Peking Union Medical College Hospital,

Chinese Academy of Medical Sciences, Peking Union Medical College,

Beijing, China; No.1 Shuaifuyuan, Wangfujing Street, Beijing 100730, China
}

(c) The Author(s). 2019 Open Access This article is distributed under the terms of the Creative Commons Attribution 4.0 International License (http://creativecommons.org/licenses/by/4.0/), which permits unrestricted use, distribution, and reproduction in any medium, provided you give appropriate credit to the original author(s) and the source, provide a link to the Creative Commons license, and indicate if changes were made. The Creative Commons Public Domain Dedication waiver (http://creativecommons.org/publicdomain/zero/1.0/) applies to the data made available in this article, unless otherwise stated. 


\section{Background}

A red blood cell transfusion decision should be made based on the patient's hemoglobin concentration $(\mathrm{Hb})$ to balance sufficient oxygen supply and transfusion-related reactions. In China, the rate of unnecessary erythrocyte transfusion reached 30.9, 95\% CI [confidence interval] = $27.1-35.0 \%$ [1] and was $28.8 \%$ in our institution; this rate was higher in surgical departments than in other departments [2]. A high number of transfusions are performed without objective indications.

In the current clinical pathway for anemia detection during intraoperative blood loss, an invasive $\mathrm{Hb}$ measurement is performed at the clinicians' discretion. Requiring clinicians to determine anemia is energy consuming and often inaccurate. Attention must be paid not only to the patient's vital signs, blood volume in the surgical field, cotton pads, and cell savers but also ongoing hemostasis procedures. The discretion of the clinician is totally subjective and is largely dependent on their clinical experience

.Moreover, $\mathrm{Hb}$ measurements are often omitted during intraoperative blood loss. Traditional $\mathrm{Hb}$ measurements such as the auto analysis of blood cells and CO-oximetry analysis require blood samples, the collection of which is invasive, time-consuming and intermittent. Considering the absence of anesthesia nurses in most hospitals in China, anesthesiologists have to send the blood sample in person, which often results in delays or is omitted in favor of completing more important work. Consequently, transfusion is often performed without any objective indications, which may result in unnecessary blood transfusions in patients lacking the necessary indications or delayed blood transfusions in bleeding patients.

Pulse CO-Oximetry (Radical 7, Masimo, Irvine, CA, USA) is a multiwavelength spectrophotometric technique providing continuous, noninvasive monitoring of total $\mathrm{Hb}(\mathrm{SpHb})$. The method is based on measurement of the differential optical density of seven different wavelengths of light passing through the finger and has received Food and Drug Administration 510(k) clearance. Although $\mathrm{SpHb}$ monitoring is not sufficiently accurate to replace invasive measurements [3, 4], studies have demonstrated acceptable correlations between the trends in $\mathrm{SpHb}$ and $\mathrm{Hb}$ [5-9]. A study reported a strong ability of $\mathrm{SpHb}$ to reliably detect changes in $\mathrm{CoOxHb}>$ $1 \mathrm{~g} / \mathrm{dl}$ [10]. SpHb may be able to inform physicians of decreases in hemoglobin concentrations in a timely and accurate manner, preventing unnecessary diagnostic blood draws and offering detailed clinical evidence for transfusion decisions during surgery.

The potential triage role of continuous, real-time monitoring of $\mathrm{Hb}$ stability should not be underestimated. The aim of this study was to investigate whether noninvasive, continuous and real-time monitoring of $\mathrm{Hb}$ could estimate the timing for further $\mathrm{Hb}$ measurements more accurately than clinicians' discretion during surgery.

\section{Methods \\ Participants}

Through a departmental quality review of transfusion practices, patients undergoing spine surgery on multiple spinal segments and cytoreductive surgery were identified; these surgeries were more likely to be associated with a sufficiently large blood loss volume to trigger anemia. The inclusion criteria were patients aged from 18 to 80 years who were scheduled for spine surgery or cytoreductive surgery, for whom the estimated blood loss was more than $15 \%$ of their total blood volume and who required an arterial catheter as a part of the standard care procedures for continuous arterial pressure monitoring and intermittent blood analysis. The exclusion criteria were an American Society of Anesthesiologists physical status score $>3$, an inability to use their upper extremities for $\mathrm{SpHb}$ monitoring, preoperative anemia (male laboratory vein $\mathrm{Hb}<12 \mathrm{~g} / \mathrm{dl}$ and female $<11 \mathrm{~g} / \mathrm{dl}$ ), hepatic insufficiency (phosphatase alkaline, aspartate aminotransferase, alanine aminotransferase $>2$ times the normal values), impaired renal function (serum creatinine $>1.5 \mathrm{mg} / \mathrm{dl}$ ), coagulation disorders (activated partial thromboplastin time $>1.5$ times the normal value or taking antiplatelet/anticoagulation drug) and pregnancy.

\section{Interventions}

\section{$\mathrm{SpHb}$ monitoring group}

In the $\mathrm{SpHb}$ monitoring group, an adhesive sensor (R2-25a), connected to the Radical- $7^{\circ}$ Pulse CO-Oximeter (software version V7740, Masimo Corp., Irvine, CA), was placed on the proximal third of the nail bed of the second, third, or fourth finger of the hand on the side opposite the arterial catheter before the induction of general anesthesia. The adhesive portion of the sensor was applied according to the directions for use and was covered with opaque shields to prevent optical interference. If the perfusion index, which is an indicator of localized perfusion, was $<1 \%$, then the sensor position was recalibrated by switching the monitor off and on.

The baseline $\mathrm{SpHb}$ was recorded after the $\mathrm{SpHb}$ was stable for at least $15 \mathrm{~min}$ following induction of anesthesia. To obtain a time-matched invasive $\mathrm{Hb}$ concentration, a blood sample was drawn through the radial arterial catheter placed in the wrist contralateral to the $\mathrm{SpHb}$ sensor. Then, the $\mathrm{CoOxHb}$ was obtained using a CO-Oximeter (Radiometer ABL800; Radiometer, Copenhagen, Denmark), which is the routine method for intraoperative $\mathrm{Hb}$ measurement in our hospital. An SpHb level $1 \mathrm{~g} / \mathrm{dl}$ lower than the baseline was set as the threshold for the alarm. When the $\mathrm{SpHb}$ monitor sounded the alarm or the surgery ended, both the 
$\mathrm{SpHb}$ and $\mathrm{CoOxHb}$ were recorded simultaneously. When clinicians deemed it necessary to take a $\mathrm{Hb}$ measurement but the pulse CO-Oximetry did not generate an alert, blood was drawn and tested to ensure the patient's safety.

\section{Standard care group}

In the standard care group, the first blood sample was drawn from the radial arterial catheter and tested for $\mathrm{CoOxHb}$ at $20 \mathrm{~min}$ following the induction of anesthesia as the baseline. Other $\mathrm{Hb}$ measurements during surgery were ordered at the discretion of the clinicians.

Intraoperative and postoperative transfusion decisions in both groups were made by the clinicians considering both the $\mathrm{CoOxHb}$ value and the clinical situation.

\section{Primary and secondary outcomes}

The hypothesis of the study was that $\mathrm{SpHb}$ monitoring could more appropriately estimate the timing for further $\mathrm{Hb}$ measurement than clinicians during surgery without creating a delay in treatment. The primary outcomes were the positive predictive values (PPVs) of SpHb monitoring and the clinicians' perception of the decrease in $\mathrm{CoOxHb}$. A true-positive finding was defined as the ability to detect a decrease in $\mathrm{CoOxHb}$ of $1 \mathrm{~g} / \mathrm{dl}$ or $\mathrm{CoOxHb}<$ $10 \mathrm{~g} / \mathrm{dl}$, whereas a false-positive finding was defined as an inability to detect stable $\mathrm{CoOxHb}$ (Fig. 1).

The secondary outcomes included a delay in treatment, the absolute accuracy and precision of $\mathrm{SpHb}$ monitoring compared with the reference method (CO-oximeter), and the accuracy of the trend in $\mathrm{SpHb}$ compared with changes in $\mathrm{CoOxHb}$. A delay in treatment was defined as a

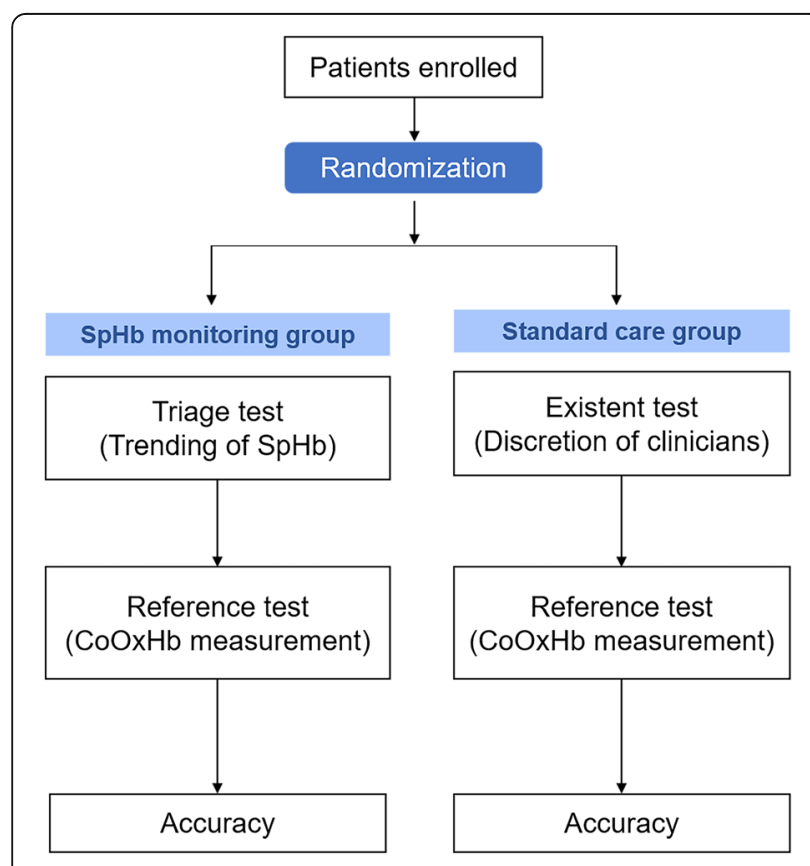

Fig. 1 Flow chart of the diagnostic randomized controlled trial decrease in $\mathrm{CoOxHb}$ to $7 \mathrm{~g} / \mathrm{dl}$, which was the intraoperative transfusion threshold in China.

\section{Sample size}

The sample size calculation was performed using internetbased software (http://www.sample-size.net/) based on the comparison of two independent proportions using exact test. In our hospital, the PPV of the clinicians' perception of a substantial decline $(>1 \mathrm{~g} / \mathrm{dl})$ in $\mathrm{CoOxHb}$ was estimated to be less than $50 \%$. Based on the results of the pilot trial, the study was designed to raise the PPV from 50 to $90 \%$ with $\mathrm{SpHb}$ monitoring, assuming a power of 0.8 and a two-sided significance level $(\alpha)$ of 0.05 . We calculated a required sample size of 20 per group. Considering that the incidence of the loss of a sufficient quantity of blood to lead to anemia during cytoreductive or spine surgeries was approximately $25 \%$, we planned to enroll 160 patients in total (80 per group).

\section{Randomization, allocation and blinding}

The trial was randomized (1:1) created using a websitegenerated (https://www.random.org/coins/) allocation list. Group allocations were concealed in sequentially numbered opaque envelopes, which were opened after the patients entered the operating rooms. After identifying the random number, the research nurse provided $\mathrm{SpHb}$ monitoring for the patient or offered standard care following the protocol.

The investigator who performed the statistical analysis was blinded to the group allocation, whereas the research nurse and anesthesiologists were not blinded.

\section{Statistical methods}

Continuous variables are expressed as the means \pm standard deviation (SD) when normally distributed and as interquartile ranges (25th to 75 th percentile) when not normally distributed. The distribution of variables was checked using visual inspection of histogram. Variables were compared using the $t$ test or Mann-Whitney $\mathrm{U}$ test when appropriate. Categorical variables are presented as numbers and percentages (\%) and were compared using Fisher's exact test.

In line with the primary objective, PPVs were presented as percentages and compared by Fisher's exact test.

For the $\mathrm{SpHb}$ accuracy analysis, the Bland-Altman test for data pairs of $\mathrm{SpHb}$ and $\mathrm{CoOxHb}$ was used to compare bias (mean error), precision (standard deviation, SD) and limits of agreement (LOA) using MedCalc (version 18.11, MedCalc Software, Acacialaan, Ostend, Belgium). The agreement between the two assays was presented by data plotting.

For the $\mathrm{SpHb}$ trend accuracy analysis, a four-quadrant plot was generated to evaluate clinically significant 
directional changes [delta $(\Delta) \mathrm{Hb}>1 \mathrm{~g} / \mathrm{dl}$ ] and a regression analysis was performed to calculate correlation coefficients ( $\mathrm{r}$ ) and 95\% CIs were reported for all data using $\mathrm{R}$ (version 3.5.1, The R Foundation, Welthandelsplatz, Vienna, Austria). The coefficient from the model could be interpreted as each unit increase of $\mathrm{SpHb}$ was associated with $\mathrm{CoOxHb}$. A two-sided $p$-value less than 0.05 was considered statistically significant. Statistical analysis was carried out using IBM SPSS for Windows (version 22.0, IBM Corporation, Armonk, New York, USA).

\section{Results}

One hundred sixty patients were assessed for eligibility from May 2018 to September 2018, of whom fifty-eight patients were excluded before allocation for various reasons (Fig. 2). In total, 69 patients completed the protocol and were included in the analysis. The participant flow diagram is shown below. No case of injury was found during the surgical procedures. The participant characteristics, operation types and intraoperative blood loss were similar between the groups (Table 1).

The incidence of unnecessary $\mathrm{Hb}$ measurement was lower in the $\mathrm{SpHb}$ monitoring group than in the standard care group. The PPV of a decrease in $\mathrm{CoOxHb}>1 \mathrm{~g} / \mathrm{dl}$ was 93.3\% based on $\mathrm{SpHb}$ monitoring and $54.5 \%$ based on the clinicians' perception $(p=0.002)$. The PPV of $\mathrm{CoOxHb}$ falling below $10 \mathrm{~g} / \mathrm{dl}$ was $86.7 \%$ vs. $50.0 \%$ for these groups $(p=0.015)$. No case had a $\mathrm{CoOxHb}<7 \mathrm{~g} / \mathrm{dl}$ with $\mathrm{SpHb}$ monitoring (Table 2).

The absolute bias \pm precision of $\mathrm{SpHb}$ monitoring compared with that of $\mathrm{CoOxHb}$ measurement was $0.29 \pm 1.03 \mathrm{~g} / \mathrm{dl}$, with $\mathrm{LOAs}=-2.30,1.72 \mathrm{~g} / \mathrm{dl}$ according to the Bland-Altman analysis (Fig. 3).

To evaluate the trends in $\Delta \mathrm{SpHb}$ and $\Delta \mathrm{CoOxHb}, 28$ data pairs were collected and displayed a strong positive correlation, with $r=0.69,95 \% \mathrm{CI}=0.53,0.82(p<0.001)$. Linear regression analysis revealed $\Delta \mathrm{SpHb}=$ $0.49^{*} \Delta \mathrm{CoOxHb}-0.13$ (Fig. 4). In the four-quadrant plot, 17 data points were outside the exclusion zone of $1 \mathrm{~g} / \mathrm{dl}$ and were located in the lower left quadrant, indicating appropriate changes in $\mathrm{SpHb}$ and $\mathrm{CoOxHb}$ in the same direction.

No difference was observed in the intraoperative transfusion units or postoperative $\mathrm{Hb}$ concentrations between the two groups (Table 3).

\section{Discussion}

In our study, a diagnostic randomized trial was designed to investigate the triage role of $\mathrm{SpHb}$ trends in the intraoperative detection of anemia. A decrease of $1 \mathrm{~g} / \mathrm{dl}$ in $\mathrm{SpHb}$ was set as the indication for the further invasive hemoglobin test. Using an absolute change in $\mathrm{CoOxHb}$ of $>1 \mathrm{~g} / \mathrm{dl}$, a concurrent absolute change in $\mathrm{SpHb}$ of

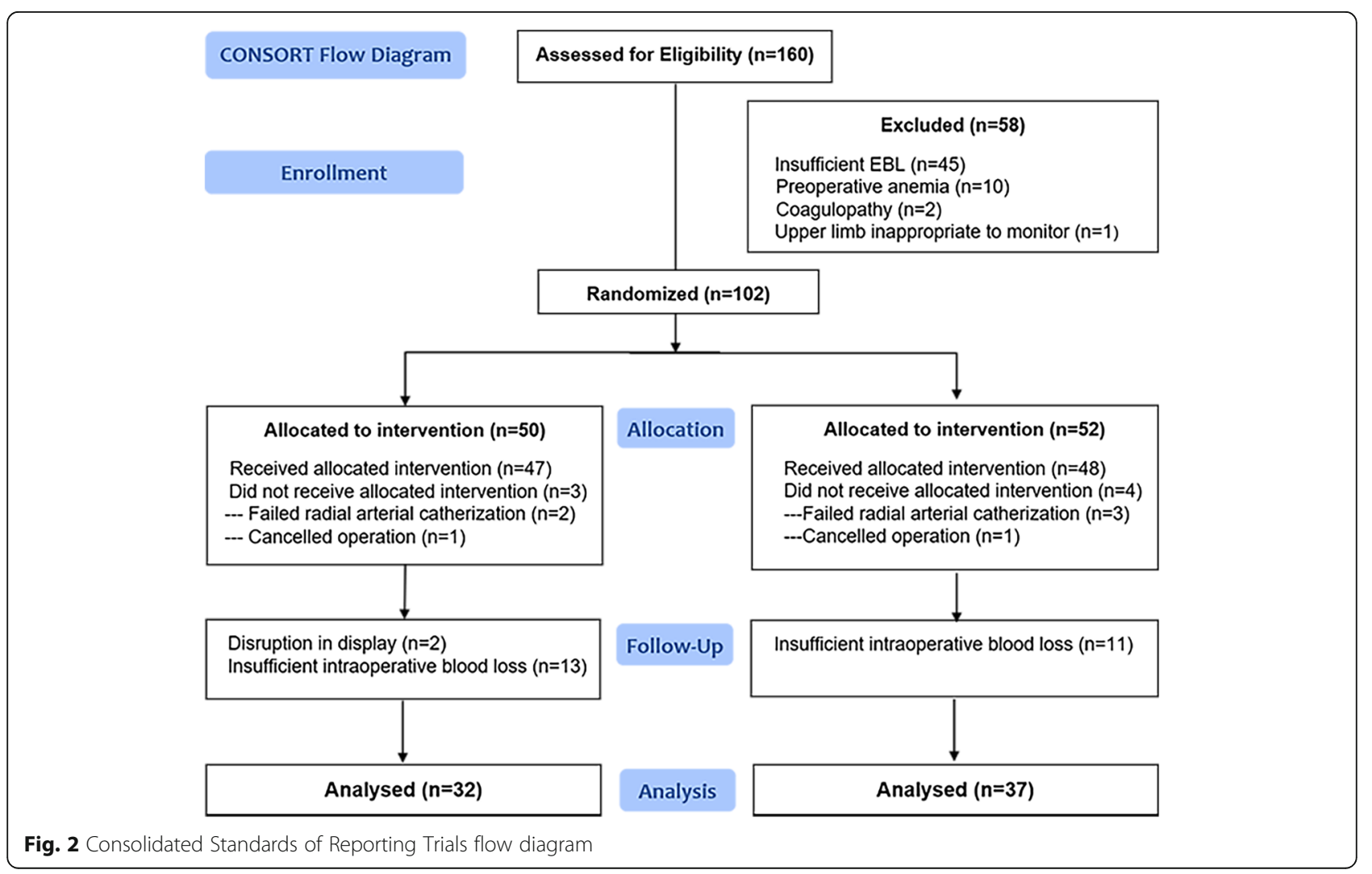


Table 1 Demographic and surgery related characteristics in $\mathrm{SpHb}$ monitoring group and Standard care group

\begin{tabular}{lll}
\hline & $\begin{array}{l}\text { SpHb monitoring } \\
\text { group }(n=32)\end{array}$ & $\begin{array}{l}\text { Standard care } \\
\text { group }(n=37)\end{array}$ \\
\hline Sex, $\mathrm{n}$ & $26(81.25 \%)$ & $30(81.08 \%)$ \\
$\quad$ Women & $6(18.75 \%)$ & $7(18.92 \%)$ \\
Men & $51.5 \pm 13.8$ & $50.4 \pm 14.4$ \\
Age, $\mathrm{y}$ & $61.8 \pm 15.0$ & $58.9 \pm 10.4$ \\
Body weight, kg & & \\
Type of surgery, $\mathrm{n}$ & $21(65.63 \%)$ & $26(70.27 \%)$ \\
$\quad$ Cytoreductive surgery & $11(34.37 \%)$ & $11(29.73 \%)$ \\
$\quad$ Spinal surgery & $11.4 \pm 1.0$ & $11.7 \pm 1.2$ \\
Preoperative hemoglobin, g/dl & $600(400$ to 1000) \\
Intraoperative blood loss, $\mathrm{ml}$ & $600(400$ to 1000$)$ & $22(59.50 \%)$ \\
Intraoperative blood loss over & $19(59.38 \%)$ & $13(35.14 \%)$ \\
15\% of total blood volume, $\mathrm{n}$ & & $24(64.86 \%)$ \\
End of surgery, $\mathrm{n}$ & & \\
$\quad$ Transferred to ICU & $10(31.25 \%)$ & \\
Back to ward & $22(68.75 \%)$ &
\end{tabular}

Data are expressed as the number of cases (\%), the mean \pm SD or the median (interquartile range). Abbreviations: ICU intensive care units

$>1 \mathrm{~g} / \mathrm{dl}$ provided a positive a predictive value of 93.3\%, which was much higher than the PPV estimated by clinicians $(50 \%)$.

Pulse CO-Oximetry is a promising technique that provides noninvasive, continuous detection of anemia but cannot be used as a substitute for invasive $\mathrm{Hb}$ measurements. Multiple factors, such as serious anemia and large amounts of vascular drugs leading to poor peripheral perfusion $[11,12]$, can reduce the accuracy of $\mathrm{SpHb}$ monitoring. We also found the decreased accuracy during blood loss. Several studies have aimed to determine whether continuous monitoring of $\mathrm{SpHb}$ can warn clinicians of anemia [13]. John Hopkins Hospital demonstrated that the $\mathrm{SpHb}$ reached a threshold of $8 \mathrm{~g} / \mathrm{dl}$ before the laboratory results in $44 \%$ of cases and was unable to identify the threshold in $48 \%$ of cases [14]. Another study found that the failure rate was $80 \%$ [15]. These studies concluded that pulse CO-Oximetry failed to warn clinicians of anemia. However, setting one fixed

Table 2 Intraoperative invasive $\mathrm{Hb}$ results

\begin{tabular}{llll}
\hline & $\begin{array}{l}\text { SpHb monitoring } \\
\text { group }\end{array}$ & $\begin{array}{l}\text { Standard care } \\
\text { group }\end{array}$ & $p$ \\
\hline $\begin{array}{l}\text { PPV of a decrease in } \\
\mathrm{CoO} \times \mathrm{Hb}>1 \mathrm{~g} / \mathrm{dl}\end{array}$ & $93.3 \%$ & $54.5 \%$ & 0.002 \\
$\begin{array}{l}\mathrm{PPV} \text { of } \mathrm{CoO} \times \mathrm{Hb} \text { falling to } \\
10 \mathrm{~g} / \mathrm{dl}\end{array}$ & $86.7 \%$ & $50.0 \%$ & 0.015 \\
$\mathrm{CoO} \times \mathrm{Hb}<7 \mathrm{~g} / \mathrm{dl}, \mathrm{n}$ & 0 & 1 & \\
\hline
\end{tabular}

Data are expressed as percentages or numbers of patients. PPVs were compared using Fisher's exact test. PPV positive predictive value

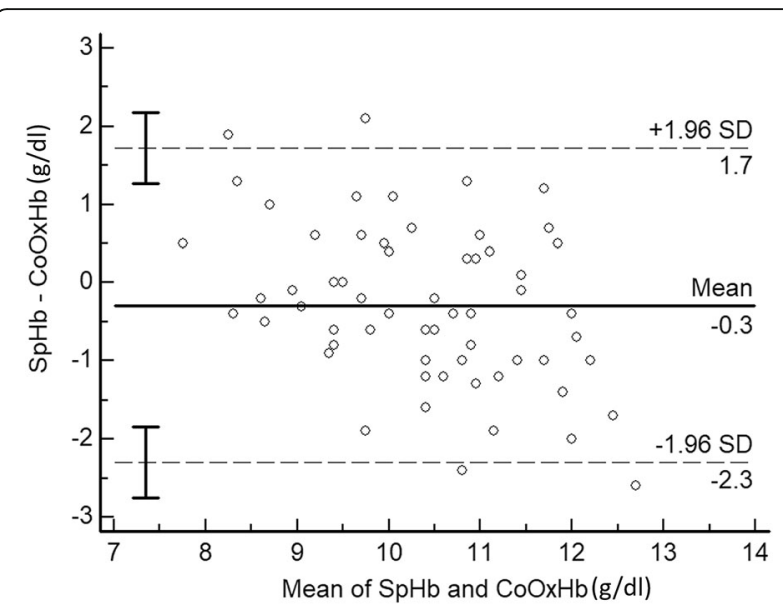

Fig. 3 Bland-Altman analysis of SpHb and $\mathrm{CoOxHb}$. Bland-Altman plot for comparison of differences in $\mathrm{Hb}$ values measured by pulse $\mathrm{CO}-$ Oximetry $(\mathrm{SpHb})$ and $\mathrm{CO}$-oximetry $(\mathrm{CoO} \mathrm{Hb})$ to the average $\mathrm{Hb}$ measurements from both methods ( $\mathrm{SpHb}$ and $\mathrm{CoO} \times \mathrm{Hb})$. The dotted lines correspond to the 95\% LOA corresponding to 1.96 SD

threshold value for all patients was inappropriate because $\mathrm{SpHb}$ overestimated the true $\mathrm{Hb}$ concentration with various errors in these studies. No study has set the decrease in $\mathrm{SpHb}$ as a threshold for the management of anemia.

Although hemodilution, active blood loss [10] and rapid transfusion [16] may influence the correlation between $\triangle \mathrm{SpHb}$ and $\triangle \mathrm{CoOxHb}$, prior studies have found that the trend in $\mathrm{SpHb}$ is a good indicator of the change in $\mathrm{Hb}$ concentration when $\Delta \mathrm{CoOxHb}$ is $>1 \mathrm{~g} / \mathrm{dl}[10,17,18]$. The consistency of the trending direction reached $86 \% \sim 95.4 \%$ $[7,18] . \Delta \mathrm{SpHb}$ was found to be positively related to $\Delta \mathrm{CoOxHb}$ with $r=0.76,95 \% \mathrm{CI}=0.57,0.86$ [7], which was consistent with our findings $(r=0.69)$. Decreases in $\mathrm{SpHb}$ probably warn of substantial changes in patients' $\mathrm{Hb}$ in a timely manner in dynamic situations. However, only a small minority of $\mathrm{SpHb}$ studies have evaluated trend accuracy, and the triage role of the trend in $\mathrm{SpHb}$ has not been evaluated.

We demonstrated the consistency between the trends in $\mathrm{SpHb}$ and $\mathrm{CoOxHb}$ in detail. The application of $\mathrm{SpHb}$ monitoring is shown in Fig. 5. Although there were various gaps existed between $\mathrm{SpHb}$ and the corresponding $\mathrm{CoOxHb}$ (indicating limited accuracy), the directions and amplitudes of the changes in SpHb were quite similar to those in CoOxHb. An interruption in the display due to poor peripheral perfusion also warned clinicians of serious anemia. The method used to evaluate the ability to track the trend in $\mathrm{SpHb}$ needs to be redefined. As a review suggested, an acceptable $\mathrm{SpHb}$ trend accuracy analysis does not require $\mathrm{SpHb}$ changes identical to invasive $\mathrm{Hb}$ changes but instead seeks to find directional agreement [3]. The stability of patients' Hb levels can be 


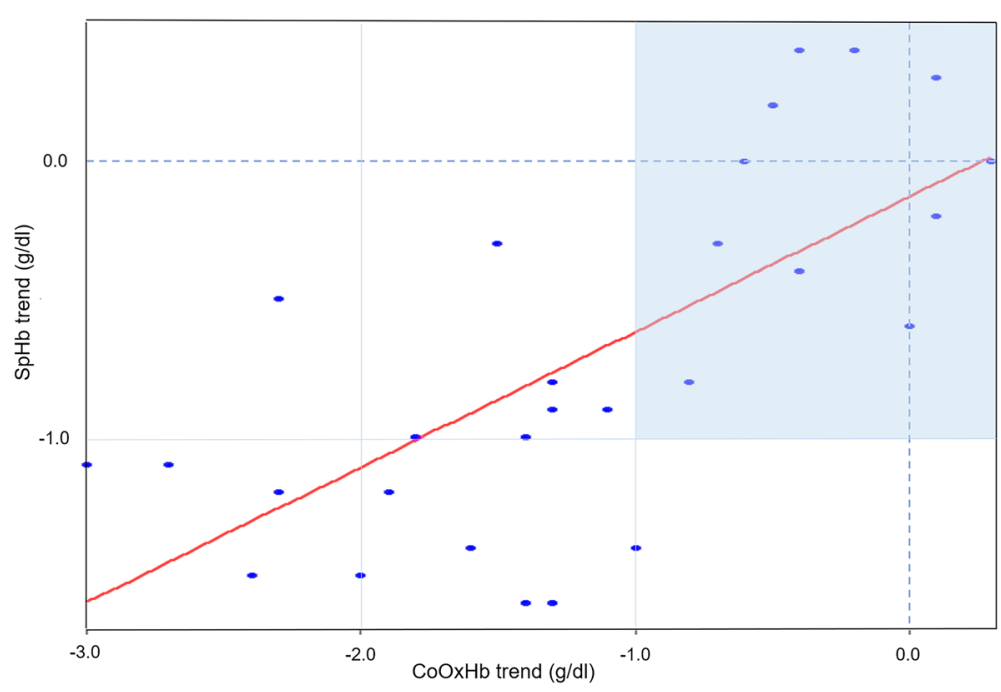

Fig. 4 Four-quadrant plot for $\Delta \mathrm{SpHb}$ and $\Delta \mathrm{CoOxHb}$. Four-quadrant graphical representation of changes in the absolute values of SpHb and $\mathrm{CoOxHb}$ (28 paired delta data points). The solid line indicates the regression line. Data pairs outside the dark area (exclusion zone) are over the clinically significant threshold of $1 \mathrm{~g} / \mathrm{dl}$

determined by appropriate interpretation of the continuous trend in $\mathrm{SpHb}$.

A novel method that takes full advantage of the trend in $\mathrm{SpHb}$ for the detection of anemia is described in this study. We found that timing the diagnostic blood draws according to changes in $\mathrm{SpHb}$ increased the PPV for anemia. Some studies that aimed to determine the PPV of $\mathrm{SpHb}$ changes compared to that of $\mathrm{Hb}$ changes reported PPVs only of $49-80 \%[10,19]$. However, in those studies, reference measurements were performed at the clinicians' discretion, which might lead to a relatively low prevalence of a substantial decline in $\mathrm{Hb}$ and a decreased PPV for the trend in $\mathrm{SpHb}$. The continuous trend in $\mathrm{SpHb}$ has not been fully exploited in clinical settings. In this study, a decrease in $\mathrm{SpHb}$ was set as the warning threshold and was able to more appropriately select the timing of invasive $\mathrm{Hb}$ measurements during surgery than clinicians. The trend in $\mathrm{SpHb}$ may play an active role in intraoperative transfusion decision-making in the future.

Although no patients received delayed treatment in the $\mathrm{SpHb}$ monitoring group, some arguments suggest that the change in SpHb may be delayed [14]. However, monitoring blood loss continuously and closely during long-term clinical work and estimating anemia accurately are difficult for doctors. Even a delayed $\mathrm{SpHb}$ may detect a change in anemia earlier than clinicians and enable doctors to focus on other important work. Therefore, setting the change in $\mathrm{SpHb}$ as an indication of intraoperative anemia should be encouraged.

In this study, no differences were found in intraoperative transfusion units or postoperative anemia between groups. Some studies found that intraoperative $\mathrm{SpHb}$ monitoring could save transfusion units [16], even reduce medical costs [20]. Although medical consumables such as sensors increase the expense, $\mathrm{SpHb}$ monitoring could save the cost of blood packaging and preservation by preventing unnecessary transfusions, leading to a reduced total cost. In fact, quantifying the improvement in patient outcomes due to use of a novel diagnostic method is extremely difficult, because other multiple therapeutic interventions may be performed at the same time. However, a timely $\mathrm{Hb}$ test result is an essential step in making a reasonable transfusion decision. Pulse CO-Oximetry may be a useful intraoperative monitor worth advocating based on clinical and

Table 3 Intraoperative transfusion units and postoperative Hb concentration

\begin{tabular}{llll}
\hline & SpHb monitoring group & Standard care group & $p$ \\
\hline Intraoperative transfusion units, $\mathrm{n}$ & $0(0$ to 1$)$ & 0 (0 to 1) & 0.938 \\
$\mathrm{CoOxHb}$ on POD1, g/dl & $10.8(9.6$ to 12.2) & $11.0(9.9$ to 11.9) & 0.705 \\
$\mathrm{CoOxHb}<10 \mathrm{~g} / \mathrm{dl}$ on POD1, \% & $31.3 \%$ & $24.3 \%$ & 0.520 \\
$\mathrm{CoOxHb}$ when discharged, $\mathrm{g} / \mathrm{dl}$ & $10.6(9.8$ to 11.1$)$ & $10.5(9.9$ to 11.3) & 0.921 \\
\hline
\end{tabular}

Data are expressed as the median (interquartile range) or proportion of cases. The median was compared using the Mann-Whitney $\mathrm{U}$ test and Fisher's exact test for categorical variables. POD 1, the first postoperative day 


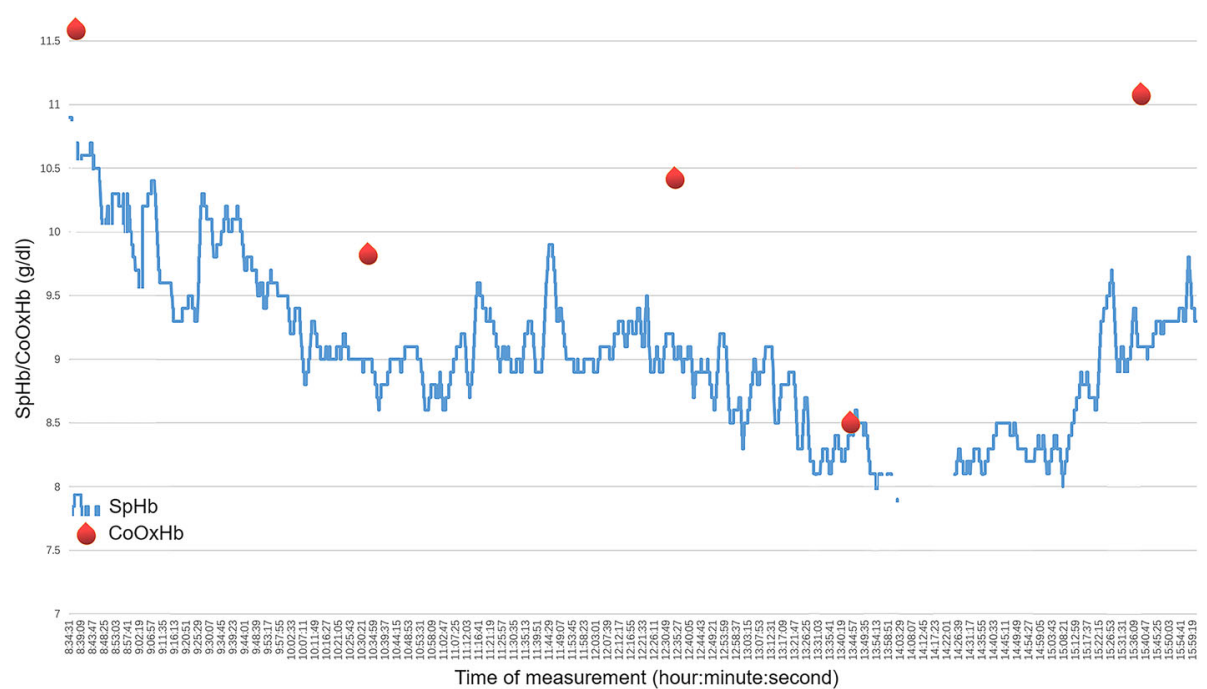

Fig. 5 Application of SpHb monitoring in our study. A diagram showing the trends in SpHb (generated by the Pulse CO-Oximetry) and intermittent $\mathrm{CoOxHb}$ measurements taken in one patient in our study. Red blood drops represent invasive CoOxHb measurements. The blue wavy line represents the continuous monitoring of SpHb during surgery

economic aspects. More studies are needed to investigate the value-added benefits of $\mathrm{SpHb}$ monitoring in blood management.

\section{Limitations}

One of the shortcomings of this study was the relatively high number of patients with a sufficiently large intraoperative blood loss volume to lead to anemia, which could have resulted in an overestimation of the SpHb monitoring PPV in the assessment of the decrease in CoOxHb. However, in this randomized trial, the PPV of the clinicians' perceptions was also overestimated. Therefore, we could draw the conclusion that $\mathrm{SpHb}$ monitoring performed better in patients with a higher risk of blood loss than clinicians' perceptions. Second, stratification analyses for various factors that affected accuracy were not performed in this study. More studies are needed to evaluate the triage role of $\mathrm{SpHb}$ monitoring in various clinical scenarios. Third, other investigators found that $\mathrm{SpHb}$ could reduce the number of transfusion units used, but this study did not influence the transfusion decision; therefore, that aspect requires further investigation.

\section{Conclusions}

This study was the first diagnostic randomized controlled trial to explore the triage role of Pulse CO-Oximetry in the intraoperative detection of anemia. We found that the trend in $\mathrm{SpHb}$ could detect a decrease in $\mathrm{Hb}$ in dynamic situations and indicate the appropriate timing for further $\mathrm{Hb}$ measurements.

\section{Abbreviations}

CoOxHb: CO-oximetry hemoglobin; POD: Postoperative day; PPV: Positive predictive value; $\mathrm{SpHb}$ : Continuous total hemoglobin
Acknowledgements

No device or material was provided by the manufacturer. The manufacturer offered no input to the design or conduct of the study or in the decision to submit the manuscript for publication.

\section{Funding}

This study was supported by the CAMS innovation Fund for Medical Sciences (CIFMS) (2016-12 M-3-024).

\section{Availability of data and materials}

The datasets used during the current study are available from the corresponding author on reasonable request.

\section{Authors' contributions}

Conception and design: BT, XRY, LX, YGH; Data collection: BT, AFZ; Data analysis: YLZ; Drafting the manuscript: BT, XRY and Revision of the manuscript after critical review: all authors. All authors read and approved the final manuscript

\section{Ethics approval and consent to participate}

This study was approved by the Ethics Committee of Peking Union Medical College Hospital (ZS-1501), and the protocol was registered at the Chinese Clinical Trial Registry (ChiCTR1800016290). Initial registration date was 24/05/ 2018. All procedures performed in this study involving human participants were in accordance with the Ethical Standards of the Institutional Ethics Committee and with the 1964 Helsinki Declaration and its later amendments or comparable ethical standards. All patients signed written informed consent before surgery.

Consent for publication

Not applicable.

\section{Competing interests}

The authors declare that they have no competing of interest.

\section{Publisher's Note}

Springer Nature remains neutral with regard to jurisdictional claims in published maps and institutional affiliations. 
Received: 21 February 2019 Accepted: 10 May 2019

Published online: 17 May 2019

\section{References}

1. Zhu C, Gao Y, Li Z, Li Q, Gao Z, Liao Y, Deng Z. A systematic review and meta-analysis of the clinical appropriateness of blood transfusion in China. Medicine (Baltimore). 2015;94(50):e2164

2. Yu X, Pang H, Xu Z, Yan H, Xu L, Du J, Ma L, Yan M, Yao Y, Jiang J, et al. Multicentre evaluation of perioperative red blood cells transfusions in China. Br J Anaesth. 2014;113(6):1055-6.

3. Barker SJ, Shander A, Ramsay MA. Continuous noninvasive hemoglobin monitoring: a measured response to a critical review. Anesth Analg. 2016;122(2):565-72.

4. Kim SH, Lilot M, Murphy LS, Sidhu KS, Yu Z, Rinehart J, Cannesson M. Accuracy of continuous noninvasive hemoglobin monitoring: a systematic review and meta-analysis. Anesth Analg. 2014;119(2):332-46.

5. Yamada H, Saeki M, Ito J, Kawada K, Higurashi A, Funakoshi H, Takeda K. The relative trending accuracy of noninvasive continuous hemoglobin monitoring during hemodialysis in critically ill patients. J Clin Monit Comput. 2015;29(1):107-12.

6. Marques NR, Kramer GC, Voigt RB, Salter MG, Kinsky MP. Trending, accuracy, and precision of noninvasive hemoglobin monitoring during human hemorrhage and fixed crystalloid bolus. Shock. 2015;44(Suppl 1):45-9.

7. Patino M, Schultz L, Hossain M, Moeller J, Mahmoud M, Gunter J, Kurth CD. Trending and accuracy of noninvasive hemoglobin monitoring in pediatric perioperative patients. Anesth Analg. 2014;119(4):920-5.

8. Gamal M, Abdelhamid B, Zakaria D, Dayem OAE, Rady A, Fawzy M, Hasanin A. Evaluation of noninvasive hemoglobin monitoring in trauma patients with low hemoglobin levels. Shock. 2018;49(2):150-3.

9. Ryan ML, Maxwell AC, Manning L, Jacobs JD, Bachier-Rodriguez M, Feliz A Williams RF. Noninvasive hemoglobin measurement in pediatric trauma patients. J Trauma Acute Care Surg. 2016;81(6):1162-6.

10. Baulig W, Seifert B, Spahn DR, Theusinger OM. Accuracy of non-invasive continuous total hemoglobin measurement by pulse CO-oximetry in severe traumatized and surgical bleeding patients. J Clin Monit Comput. 2017;31(1): 177-85

11. Akyildiz B. Noninvasive measurement of hemoglobin using spectrophotometry: is it useful for the critically ill child? J Pediatr Hematol Oncol. 2018;40(1):e19-22.

12. Saito J, Kitayama M, Amanai E, Toyooka K, Hirota K. Impact of acute changes in perfusion index and blood pressure on the accuracy of non-invasive continuous hemoglobin concentration measurements during induction of anesthesia. J Anesth. 2017;31(2):193-7.

13. Yang S, Hu PF, Anazodo A, Gao C, Chen H, Wade C, Hartsky L, Miller C, Imle C, Fang R, et al. Trends of hemoglobin oximetry: do they help predict blood transfusion during trauma patient resuscitation? Anesth Analg. 2016;122(1): $115-25$

14. Xu T, Yang T, Kim JB, Romig MC, Sapirstein A, Winters BD. Evaluation of noninvasive hemoglobin monitoring in surgical critical care patients. Crit Care Med. 2016:44(6):e344-52.

15. Joseph B, Hadjizacharia P, Aziz H, Snyder K, Wynne J, Kulvatunyou N, Tang A, O'Keeffe T, Latifi R, Friese R, et al. Continuous noninvasive hemoglobin monitor from pulse ox: ready for prime time? World J Surg. 2013;37(3):525-9.

16. Saito J, Kitayama M, Oishi M, Kudo T, Sawada M, Hashimoto H, Hirota K. The accuracy of non-invasively continuous total hemoglobin measurement by pulse CO-oximetry undergoing acute normovolemic hemodilution and reinfusion of autologous blood. J Anesth. 2015;29(1):29-34.

17. Berkow L, Rotolo S, Mirski E. Continuous noninvasive hemoglobin monitoring during complex spine surgery. Anesth Analg. 2011:113(6):1396-402.

18. Colquhoun DA, Forkin KT, Durieux ME, Thiele RH. Ability of the Masimo pulse CO-oximeter to detect changes in hemoglobin. J Clin Monit Comput. 2012;26(2):69-73.

19. Bridges $\mathrm{E}$, Hatzfeld JJ. Noninvasive continuous hemoglobin monitoring in combat casualties: a pilot study. Shock. 2016;46(3 Suppl 1):55-60.

20. Ribed-Sanchez B, Gonzalez-Gaya C, Varea-Diaz S, Corbacho-Fabregat C, Perez-Oteyza J, Belda-Iniesta C. Economic analysis of the reduction of blood transfusions during surgical procedures while continuous hemoglobin monitoring is used. Sensors (Basel). 2018;18(5).

\section{Ready to submit your research? Choose BMC and benefit from:}

- fast, convenient online submission

- thorough peer review by experienced researchers in your field

- rapid publication on acceptance

- support for research data, including large and complex data types

- gold Open Access which fosters wider collaboration and increased citations

- maximum visibility for your research: over $100 \mathrm{M}$ website views per year

At $\mathrm{BMC}$, research is always in progress.

Learn more biomedcentral.com/submissions 